\title{
Effect of cypermethrin, a pyrethroid insecticide on dynamics of soil microflora
}

\author{
Bijay Kumar Sethi ${ }^{1,2^{*}}$, Subhashree Pradhan $^{1}$, Narayan Behera ${ }^{1}$, Santi Lata Sahoo ${ }^{1}$ \\ 1 Applied Microbiology Laboratory, Post Graduate Department of Botany, Utkal University, Vani Vihar, Bhubaneswar-751004, Odisha, India. \\ ${ }^{2}$ Department of Biotechnology, MITS School of Biotechnology, 2 (P), Infocity, Patia, Chandaka Industrial Estate, Bhubaneswar-751024, Odisha, India.
}

\begin{tabular}{|c|c|}
\hline ARTICLE INFO & ABSTRACT \\
\hline $\begin{array}{l}\text { Article history: } \\
\text { Received on: } 19 / 06 / 2015 \\
\text { Revised on: } 06 / 07 / 2015 \\
\text { Accepted on: } 22 / 07 / 2015 \\
\text { Available online: } 22 / 10 / 2015\end{array}$ & $\begin{array}{l}\text { Soil samples were collected from garden of P.G. Department of Botany, Utkal University, Odisha India. The } \\
\text { physical analysis of soil revealed that texture of the soil was sandy loam with } \mathrm{pH} 5.7 \text {, temperature } 34.6^{\circ} \mathrm{C}, 5.7 \% \\
\text { water content and } 67.3 \% \text { water holding capacity, respectively. Utmost numbers of Aspergillus species with other } \\
\text { fungi were isolated from garden soil }\left(5 \times 10^{5} \mathrm{CFU} / \mathrm{g}\right) \text {. Total } 19 \text { fungal taxa were isolated from all the samples } \\
\text { studied. The isolated species were belonging to } 8 \text { genera representing the genus Aspergillus as dominant one. } \\
\text { Total twelve fungal species of six genera were recorded from air of the pesticide treated soil area. Soil treated }\end{array}$ \\
\hline $\begin{array}{l}\text { Key words: } \\
\text { Aspergillus, cypermethrin, } \\
\text { protease, soil. }\end{array}$ & $\begin{array}{l}\text { with } 600 \mathrm{ppm} \text { cypermethrin exhibited ten fungal species. Out of which, A. flavus appeared in greater number as } \\
\text { compared to other fungi. Similarly, A. candidus was contributed highest percentage followed by A. flavus in } \\
\text { dilution plate technique. Total eight species of fungi belonging to three genera were found when soil was treated } \\
\text { with cypermethrin at a concentration of } 800 \mathrm{ppm} \text {. A. candidus and A. flavus were isolated in highest number at } \\
1000 \mathrm{ppm} \text { cypermethrin. But, in direct plate technique, A. flavus was found to be the dominant species followed } \\
\text { by A. terreus and } \text { A. niger at } 1000 \text { and } 1200 \mathrm{ppm} \text { concentration of cypermethrin, respectively. Soil treated with } \\
\text { cypermethrin at } 1400 \mathrm{ppm} \text { concentration exhibited that } \text { A. awamori was the dominant species isolated followed by } \\
\text { A. terreus and Mucor hiemalis both in direct and dilution plate techniques. Among all the isolates screened for } \\
\text { protease activity, A. terreus } \text { was potent enough for this production. }\end{array}$ \\
\hline
\end{tabular}

\section{INTRODUCTION}

Soil is the most vibrant living habitat which comprises a variety of flora and fauna and microorganism (actinomycetes, arthropods, bacteria, crustaceans, earthworms, fungi and nematodes). But in the contemporary era of agriculture and farming, the pesticides have been used extensively and occupied a pivotal place in cultivation of crops. Its uncontrolled use has generated countless hazards and dilemma including the environmental pollutions. The pesticides have cumulative effect on target and non-target microflora that may greatly hamper the biological processes like, decomposition, degradation, transformation, clay-humus-microbes' interaction, microbemicrobe interaction and plant-microbe interaction. It also acts on the resistance factors of microorganisms tending towards the

* Corresponding Author

Bijay Kumar Sethi,Applied Microbiology Laboratory, Post Graduate Department of Botany, Utkal University, Vani Vihar, Bhubaneswar751004, Odisha, India. Email :reach4bijay@ gmail.com vanishing from the soil. Frequent long term application of pesticides to the soil may accumulate the recalcitrant chemicals that may possess permanent detrimental effect on soil microbiological and biochemical activities. Currently, microorganisms are exploited in many ways to get valuable products which include enzymes, secondary metabolites, therapeutic agents and industrial products. Such potential microorganisms are usually isolated from the soil sample. Among such microbes, filamentous fungi dominate our globe as sources of food, plant and animal pathogens and for biosynthesis of other worthy products.

Besides to this, they are the critical components of our natural and agricultural ecosystem. Due to the application of a variety of hazardous chemicals to the cultivated lands, the growth, survival, continuity and community of fungi is significantly affected. During 1930s, the organophosphorus pesticides in Germany have possessed high mammalian toxicity and also perturb the functional dynamics of many microbial communities. For example, due to the long-term application of atrazine, cellulaseproducing-bacteria were permanently removed from an apple orchard kept free from direct vegetative cover [1]. 
Repeated annual applications of paraquat up to 18 years was found to have escalating populations of aerobic \& cellulolytic bacteria and actinomycetes, but diminished fungal populations [2]. Rai [3] reported that 15 years of annual application of 2,4-D decreased microbial biomass by $15-20 \%$, while long-term applications of paraquat [2], trifluralin [4] and atrazine [5] were all reported to have a decline in microbial biomass. Fungicides of both systemic and non-systemic are reported to have an undesirable effect on the colonization of the roots of crop plants by arbuscular mycorrhizal (AM) fungi with reduced phosphorus uptake [6]. The fungicide mancozeb and the nematicide "aldicarb" when applied to soil individually did not affect the colonization of sugarcane roots by arbuscular mycorrhizal fungi, but reduced colonization when applied in combination [7]. Besides that, Other similar reports include a decrease in dehydrogenase and urease activity following long-term (15 years) application of 2,4-D (isoctyl ester formulation) [3], a decrease in dehydrogenase and arylsulfatase in South Australian soils following long-term applications of atrazine [5], and a decrease in phosphatase activity following long-term applications of glyphosate [8]. A number of pesticides used in Australian agriculture (endosulfan, paraquat, glyphosate and diuron) have a short-term harmful impact on soil respiration which may persevere for 6-8 weeks after application. The prospective for pesticides to amend the soil microbial community without necessarily affecting the soil biology has encouraged the addition of novel methods for swift diagnosis of microbial miscellany in pesticide approval protocols concerning the environmental insinuations of amended microbial diversity to soil productivity [9]. Therefore, appraisal of soil microbial community is regarded to be a constructive technique to evaluate the impact of agricultural practices on soil health [7, 10, 11].

Therefore, as the search for new microbial sources is a continual and essential exercise, the present study aimed at the isolation, identification and effect of various pesticides on dynamics of soil microflora.

\section{MATERIALS AND METHODS}

\subsection{Chemicals, media and reagents}

All the chemicals, media and reagents used in this study were of Analytical grade (AR) and procured from Hi-Media, Merck and Sigma Chemicals. The pesticide, cypermethrin was purchased from a local agricultural based outlet of Bhubaneswar, Odisha, India.

\subsection{Selection of the experimental field}

An experimental field $(5 \times 5 \mathrm{~m})$ was selected inside the garden of the P. G. Department of Botany, Utkal University, Odisha, India. All small plants and other litter deposited were removed completely. The field was left under natural condition for about fifteen days before the soil sampling. Surface soil was removed carefully and freed from decomposed plant residues.

Soil samples were collected in two different parts for soil and microbial population analysis. New polythene bags were used to collect soil samples for edaphic properties. Sample in bulk, about $1 \mathrm{Kg}$ was brought to the laboratory, dried in shade under fan and gently crushed to get semi fine soil particles. Crushed soil was passed through a general mash and about $100 \mathrm{~g}$ soil was sealed in a small polythene packet and stored under laboratory condition until use. Ten such packets were prepared and kept in laboratory for study of soil parameters.

Other part of the soil was collected aseptically for fungal population analysis. Ten such samples of the soil within a depth of $5 \mathrm{~cm}$ were collected, brought to laboratory immediately and stored in refrigerator at $4{ }^{\circ} \mathrm{C}$.

The samples thus collected were processed for fungal enumeration on the same day or on the next day positively to avoid the loss of viability of certain microbes that fail to stand condition away from nature.

\subsection{Soil analysis}

Physical parameters of the soil were studied such as, soil texture, $\mathrm{pH}$, temperature, water content and water holding capacity (WHC).

\subsection{Effect of pesticides on soil microflora}

Cypermethrin was selected to evaluate its effect on soil microflora. Cypermethrin is generally available in $10 \%$ E.C. in the market with a recommended dose of $1000 \mathrm{ppm}$. Five different concentrations i.e. 600, 800, 1000, 1200 and 1400 ppm were applied to the experimental soil. Same size earthen pots were taken and $2 \mathrm{~kg}$ hand crushed garden soil was filled in each pot. The pesticide solutions were separately added and mixed in each pot with an amount so as to provide $60 \%$ WHC to the soil .Samples were drawn after 7days of treatment for microflora analysis.

\subsection{Isolation of microorganisms \\ 2.5.1 Dilution plate technique}

The collected soil samples were processed for analysis by serial dilution followed by pour-plate technique as per Sethi et al. [12] method. The dilutions of $10^{-4}, 10^{-5}$ and $10^{-6}$ thus prepared were platted using sterilized potato dextrose agar (PDA) medium separately in three replicates taking $1 \mathrm{ml}$ from individual dilution tubes. The prepared plates were incubated upside down in an incubator at $28^{\circ} \mathrm{C} \pm 2{ }^{\circ} \mathrm{C}$. Number of Colony Forming units developed after 3, 5 and 7days on PDA plates were counted.

Similarly, prepared PDA plates were exposed for a period of 15 min in the garden to ensure the number of microorganisms present in the air.

\subsubsection{Soil plate technique}

About $0.1 \mathrm{~g}$ of soil sample was taken in a clean and sterilized perti plate. One to two drops of sterile water was added to moisten the soil followed by proper teasing to get fine particles. The plate with sample was shaken repeatedly for proper dispersion of soil particles. To it, $15-20 \mathrm{ml}$ of sterilized, warm $\left(\sim 45^{\circ} \mathrm{C}\right)$ agar medium was added and mixed properly. Plates thus prepared were incubated at $28 \pm 2{ }^{\circ} \mathrm{C}$ for seven days and examined for total count 
of colonies and identification. Enumeration of fungal population was calculated from dilution plate technique and percentage frequency from direct soil plate technique.

\subsection{Identification of the isolated fungi}

All the isolated fungi were identified based on macro (colony morphology) and microscopic characteristics [13, 14].

\subsection{Screening for proteolytic activity}

Screening for protease activity was performed on prepoured Czapek Dox agar plates supplemented with $1 \%$ casein (w/v) by point inoculation with mycelium/spores of fungal isolates [15]. Petri plates were stained with Nessler's reagent and the hydrolyzing zones were measured and photographed.

\subsection{Statistical analysis}

All the experiments were performed in triplicates. The mean, standard deviation and standard error of mean were calculated and represented in the results.

\section{RESULTS AND DISCUSSION}

Soil is the house of all living forms and the laboratory within which alterations are carried out that facilitate the life to go on. Hence, Soil is also universally known as the elixir of many organisms. But, among different layers of soil, the upper surface of the layer within 10-12 inch depth is the most productive zone, densely populated with flora, fauna and microbes, which accomplish major transformations in soil. Nonetheless, garden soil was also reported to be a preferred source for isolation of microbes, presumably because of the various biological activities that create suitable conditions for life to exist [16].

Soil samples were collected mainly from garden of P.G. Department of Botany, Utkal University, Odisha, India. This area was selected because it is rich in organic pollutants due to various garden practices and dumping of plant materials.

\subsection{Properties of soil}

Before stepping into the different aspects of the study, the physical properties of soil were analyzed. The texture of the soil was sandy loam with a $\mathrm{pH}$ of 5.9 , temperature $31.5^{\circ} \mathrm{C}, 5.7 \%$ water content and $69.2 \%$ water holding capacity, respectively. The $\mathrm{pH}$ values clearly indicate that the soil is moderately acidic in nature. Acidic soils are usually deprived in nutrient content and consequently, organic carbon, organic matter, organic nitrogen and available phosphorus are least. Water holding capacity of sandy soil is constantly less as compared to other types of soil and lofty in pit soils where humus content is very high. Texturally, the present soil is sandy loam with low organic content and, therefore, the WHC is not high.

\subsection{Soil mycoflora study}

Maximum numbers of fungal species were isolated from the air followed by soil of garden of P.G. Department of Botany.
Utmost numbers of Aspergillus species and other fungal species were obtained from the garden soil of P.G. Department of Botany $\left(5 \times 10^{5} \mathrm{CFU} / \mathrm{g}\right)$. The frequency distribution of all examined samples for fungi and Aspergillus species count varied within the range $\leq 5 \%$ to $15 \%$. In all soil samples, Aspergillus species was the most dominated species followed by Aspergillus terreus. Fleet and Mian [17] have also reported similar type of findings for the garden soil. All soil samples were enumerated using both dilution (pour) plate and direct plate methods. The mixed fungal plates thus obtained were pure cultured for further separation of the individual colony. Most of the fungi isolated belong to the sub division Deuteromycotina and two members were recognized under Zygomycotina. A total of 19 fungal taxa were isolated from all the samples studied (Table 1). All the species isolated were belonging to 8 genera and the genus Aspergillus was the dominated one. Aspergillus species were the dominant group having about 9 taxa. Curvularia and Alternaria have represented by 2 taxa each. Fusarium, Mucor, Penicillium, Rhizopus nigricans and Trichoderma recorded here were represented by only one species each (Table 1).

Mucor hiemalis and Rhizopus nigricans were the two isolates recorded from the sub division Zygomycotina (Fig 1a). One unsporulated white sterile mycelium was also reported from the air sample (Fig. 1b). Surface of the soil was initially scraped by a sterilized spatula followed by horizontally running a sterilized test tube to collect about 10-20 gm of soil.

\subsection{Aeromycoflora study}

Total twelve fungal species belonging to six genera were recorded from air of the pesticide treated soil area. Genus Aspergillus was comprised of four species, Curvularia two species and others represented by single species. It is clear from the Fig. $1 \mathrm{~b}$ that Curvularia lunata was the dominant species that contributed maximum to the total isolates and constituted $16.1 \%$ of the sum total colonies followed by Curvularia pallascens which contributed about $13.8 \%$ of the total isolates followed by Aspergillus flavus, Aspergillus niger, Aspergillus terreus, Aspergillus sp., Mucor hiemalis, Penicillium sp., white sterile mycelia, Rhizopus nigricans and Fusarium oxysporum. Fungus, Fusarium oxysporum was contributed only by $2.09 \%$ of the total population (Fig. 1b). Air sampling is a most suitable technique to get spores settled on agar medium and grow to colonies in a period of 3-4 days. In spite of certain minor inadequacies, this is widely accepted by various workers. This technique of sampling is more appropriate to check the contamination of air spora [18]. The presence study on aeromycoflora was mainly conducted in the garden environment of Department of Botany, Utkal University. Of all the members Aspergillus niger, A. terreus and A. flavus were the dominant ones. A. niger is an aeroallergens causes aspergillosis, a serious bronchital infections. Aspergillus flavus is very well known for production of aflatoxin. This toxin is fatal to birds and hazardous to metabolic function. Chakraverty and Sinha [19] have also studied the incidence of $A$. parasiticus for a period five months in indoor and outdoor environment. 
Table 1: Occurrence of fungal species in air, soil and pesticide treated soil.

\begin{tabular}{|c|c|c|c|c|c|c|c|c|}
\hline \multirow{3}{*}{ Name of the Fungus } & \multicolumn{8}{|c|}{ Samples } \\
\hline & \multirow{2}{*}{ Air } & \multirow{2}{*}{ Soil (SP) } & \multirow{2}{*}{ Soil (DP) } & \multicolumn{5}{|c|}{ Cypermethrin treated soil (conc. in ppm) } \\
\hline & & & & 600 & 800 & 1000 & 1200 & 1400 \\
\hline Alternaria alternata & - & + & - & - & - & - & - & - \\
\hline Alternaria tenius & + & - & - & - & - & - & - & - \\
\hline Aspergillus awamori & - & + & + & - & - & - & - & + \\
\hline Aspergillus candidus & - & - & + & + & + & + & + & + \\
\hline Aspergillus flavus & + & + & + & + & + & + & + & + \\
\hline Aspergillus fumigatus & - & + & + & + & + & - & - & + \\
\hline Aspergillus japonicus & - & - & - & - & - & - & + & + \\
\hline Aspergillus niger & + & + & + & + & + & + & + & \\
\hline Aspergillus tamari & - & + & + & + & + & + & + & + \\
\hline Aspergillus terreus & + & + & + & + & + & + & + & + \\
\hline Aspergillus species & + & + & + & + & + & + & - & - \\
\hline Curvularia lunata & + & - & - & - & - & - & - & - \\
\hline Curvularia pallusens & + & - & - & - & - & - & - & \\
\hline Fusarium oxysporum & + & - & - & + & - & - & - & - \\
\hline Mucor hiemalis & + & - & + & - & + & + & + & + \\
\hline Penicillium sp. & - & + & - & - & - & - & - & - \\
\hline Rhizopus nigricans & + & - & - & + & - & - & - & - \\
\hline Trichoderma viridae & - & + & - & - & - & - & - & - \\
\hline White sterile mycellium & + & - & - & - & + & - & - & - \\
\hline
\end{tabular}

+: present; -: absent; SP: Soil plate technique; DP: Dilution plate technique

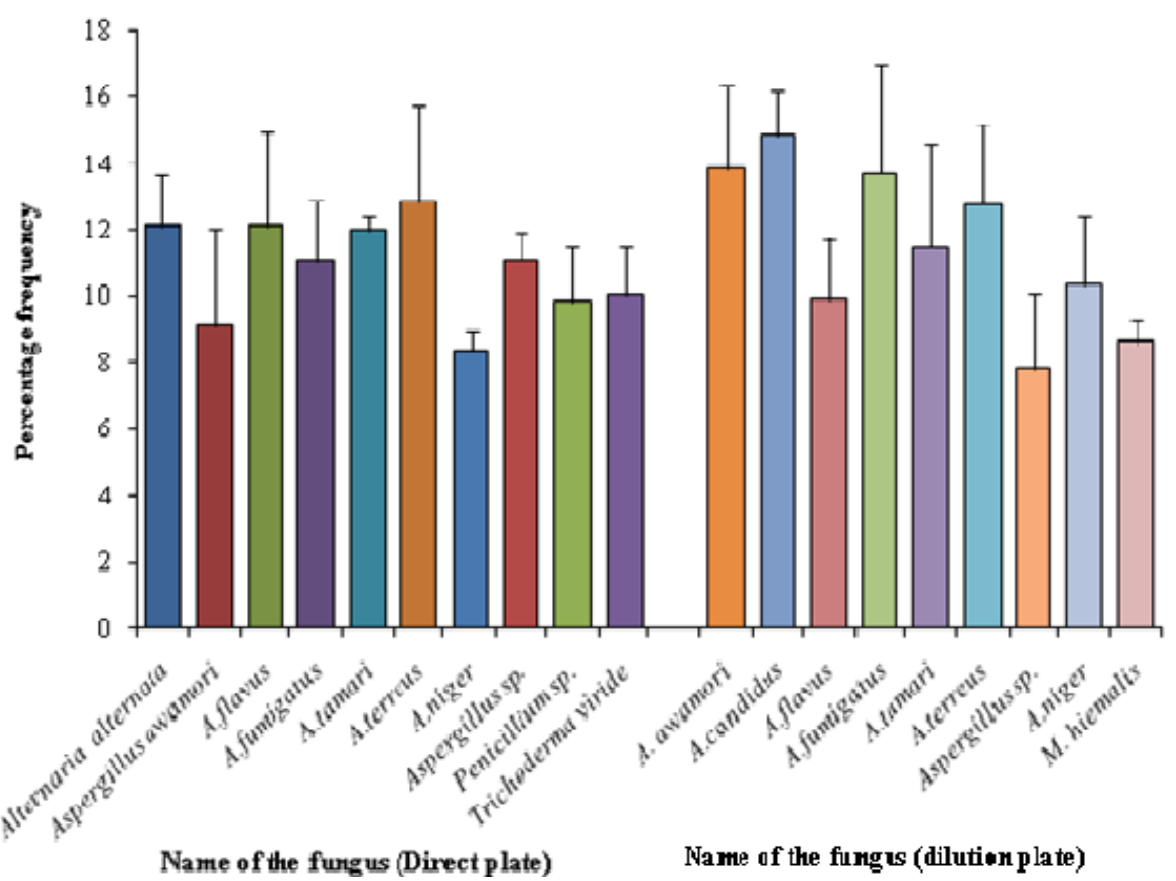

Fig. 1a: Percentage frequency of the isolated fungi recorded from soil (direct and dilution plate) (mean values \pm SEM) of botanical garden, P.G. Department of Botany, Utkal University, Odisha, India.

\subsection{Identification of isolated fungi}

All these fungi were identified by the aid of laboratory experiences, references of certain monographic books $[13,14]$ and NCFT, New Delhi (Fig. 2a).

The colony colour and texture of $A$. terreus on PDA was as follows; colour: cinnamon to brown, RPC: brownish yellowish, appearance: powdery to dusty: form: irregular to rounded, margin: erose, elevation: raised and furrowed. Phase contrast microscopic study revealed that the conidiophores of $A$. terreus were found to be $100-250 \times 4.5-6 \mu \mathrm{m}$, vesicle: hemispherical (10-15 $\mu \mathrm{m}$ long), merging into supporting conidiophores, biseriate sterigmata with primaries crowed, parallel $(5-7 \times 2-2.5 \mu \mathrm{m})$, secondaries closely packed $(5.5-7 \times 1.5-2 \mu \mathrm{m})$. Conidia were found to be short, smooth, colourless, globose to slight elliptical with $1.5-2.5 \mu \mathrm{m}$ in diameter. Philides were biseriate; vesicle: round with loosely radiate head. Hulle cells were solitary, round and produced directly on hyphae with colourless head (Fig. 2b, c, d).

\subsection{Effect of cypermethrin on fungal community in soil}

The fungal taxa isolated by direct plate method from the soil treated with cypermethrin (600ppm concentration) with their percentage contribution recorded by direct plate method are given in Fig.3a. It was shown from the figure that Aspergillus flavus appeared in greater numbers than rest of the fungi. In total ten 
species of fungi belonging to four genera were noted. Aspergillus was the dominant genus comprised of seven species and others were found as single species. Among the taxa, Mucor hiemalis was represented with lesser frequencies as compared to the others. Similarly, Aspergillus candidus was contributed highest percentage followed by Aspergillus flavus in dilution plate technique. The third dominant one was Aspergillus terreus. Mucor hiemalis was found to have minimum contribution as compared to the total population isolated (Fig. 3a). Total eight species of fungi belonging to three genera were found when soil was treated with cypermethrin at a concentration of $800 \mathrm{ppm}$. Genus Aspergillus was comprised of seven species, Mucor hiemalis was only one along with a single white sterile mycelium (WSM). Among the taxa, A. fumigatus was found with lesser frequencies as compared to other isolates (Fig. 3b). Results of the dilution plates treated with $800 \mathrm{ppm}$ cypermethrin are also given in (Fig. 3b). Data are presented in percentage contribution of each individual isolation. A. flavus was always contributed highest percentage followed by A. candidus. Among all, the third dominated species was found to be $A$. terreus. Figure $3 \mathrm{~b}$ explains about the fungal taxa isolated from soil treated with cypermethrin (1000ppm) with their percentage frequencies and percentage contribution recorded by direct and dilution plate methods. A. candidus and A. flavus were appeared in greater number than other fungi. In total, only six species of fungi were belonging to the genus Aspergillus. Among all the genera, $M$. hiemalis was found in least number. In direct plate technique, A. flavus was found to be the dominant species as compared to other fungal isolates at $1000 \mathrm{ppm}$ concentration of cypermethrin. Genus Aspergillus was comprised of six species followed by only one species of M. hiemalis. Except A. flavus, others fungi were found to be merely equal in number. Results of the dilution plate treated with cypermethrin $1000 \mathrm{ppm}$ concentration are presented in percentage contribution of individual isolation (Fig. 3b). A. candidus and A. flavus were found in highest number followed by A. niger and A. terreus. Results of the dilution plate treated with cypermethrin (1200 ppm concentration) are represented in percentage contribution. In this finding, A. flavus was recorded in greater number followed by $A$. terreus and $A$. niger (Fig. 3c). Fungi isolated from soil treated with cypermethrin at $1400 \mathrm{ppm}$ concentration with their percentage frequencies recorded by direct plate method are represented in Fig. 3d. A. awamori was found in highest number followed by $A$. terreus and $M$. hiemalis. Results of the dilution plate treated with cypermethrin $1400 \mathrm{ppm}$ are shown in Fig. 3d. In this study, A. awamori was found in highest number followed by A. flavus and A. tamari. Mucor hiemalis was represented with least number.

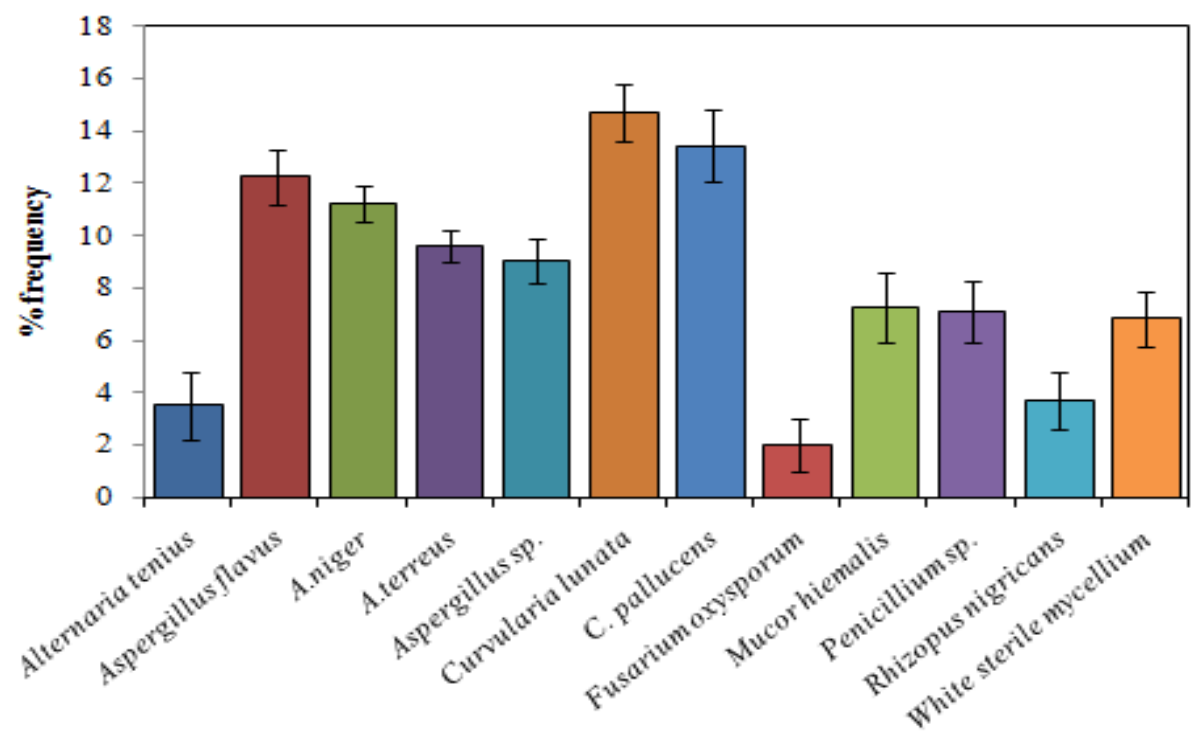

Name of the isolated organisms from air

Fig. 1b: Percentage frequency of the isolated fungi recorded from air (mean values \pm SEM) of botanical garden, P.G. Department of Botany, Utkal University, Odisha, India.

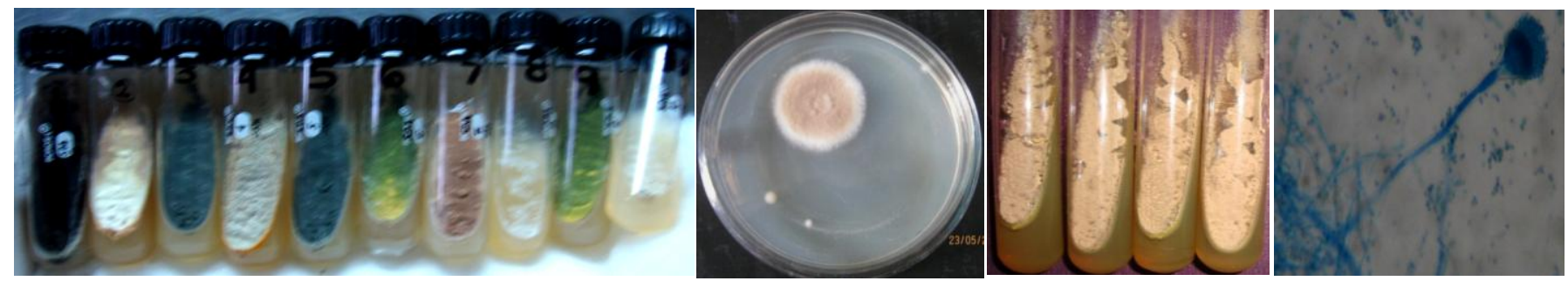

Fig. 2 a: Fungal pure culture slants isolated from soil sample; b: pure culture plate of A. terreus, c: Sub culturing of A. terreus d: phase contrast microscopic view of A. terreus 


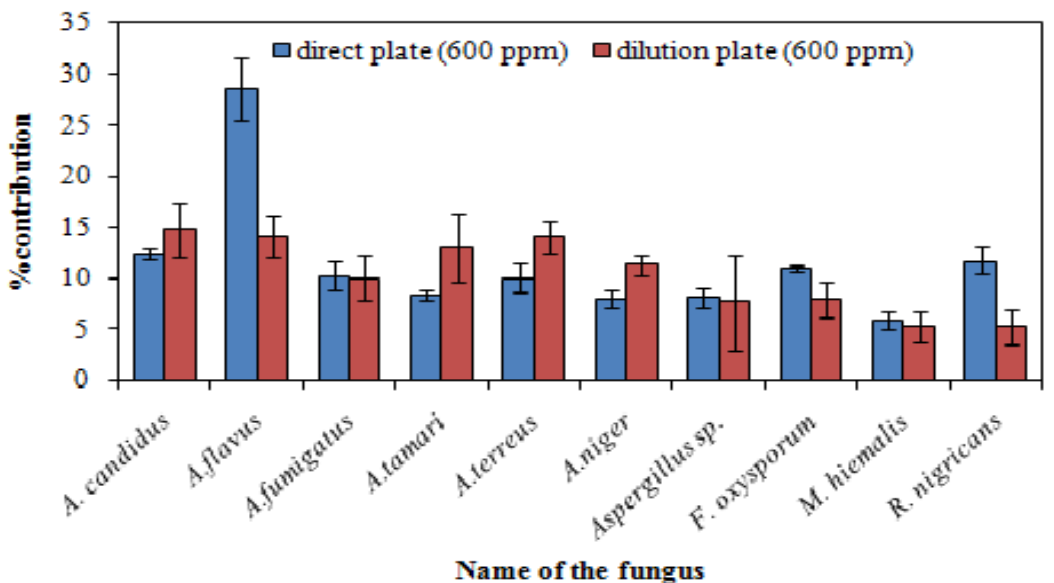

A

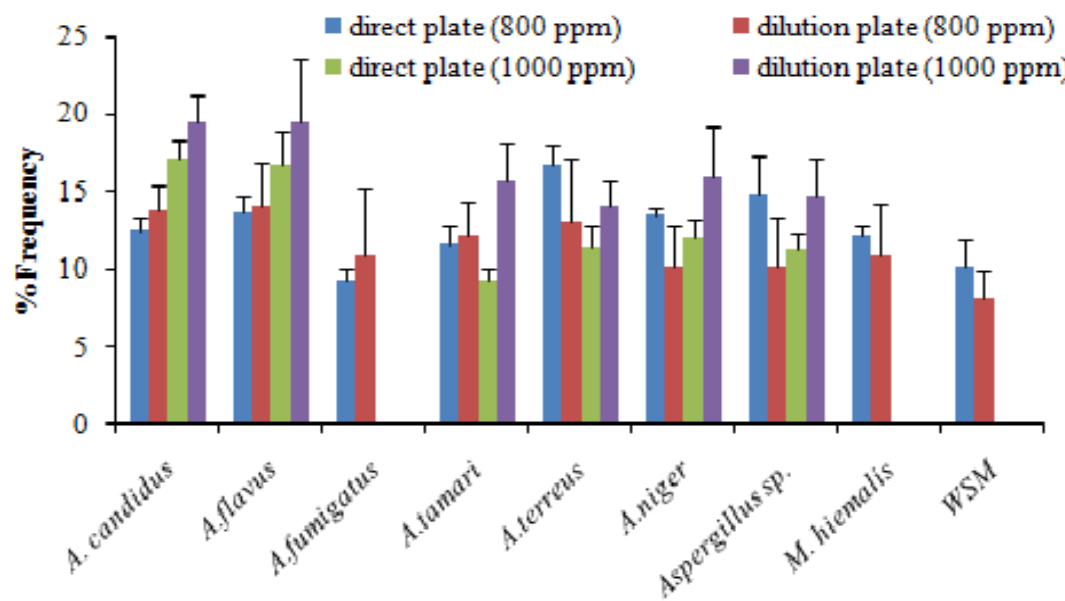

Name of the isolated fungi

B
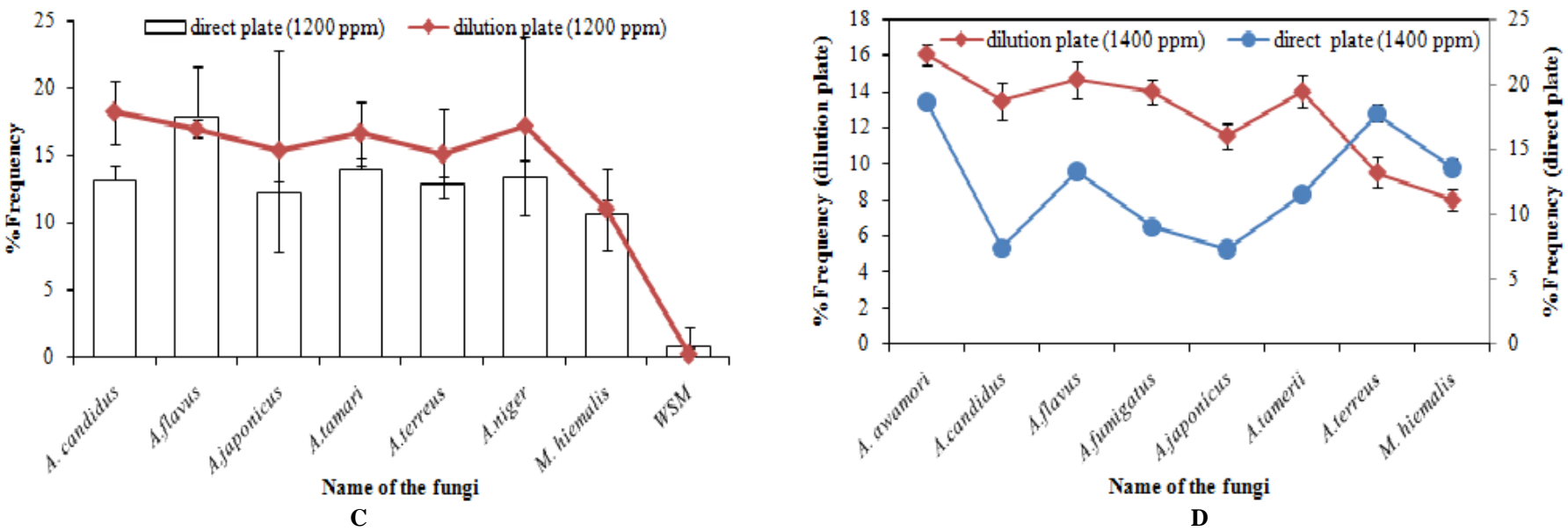

D

Fig. 3 (a-d): Fungi with their percentage contribution and percentage frequency recorded from cypermethrin treated soil (Direct and Dilution plate) (mean values \pm SEM)

\subsection{Protein hydrolyzing ability of isolated fungi}

For the biosynthesis of industrially important enzymes in bulk, isolation, identification and characterization of novel strain is a never-ending process. Furthermore, proteases produced from microorganisms are either constitutive or induced in the presence of specific substrates and their biosynthesis is generally persuaded by alteration in fermentation conditions [20]. So, casein, a milk protein was supplemented with the medium and evaluated for protease production by the native isolates. All test strains showed best hydrolyzing zone formation potential at $\mathrm{pH} 8.5 \pm 0.2$. Among 
the ten test strains, performance of $A$. terreus was the best in casein hydrolyzing activity (Fig. 4). Strains like M. hiemalis and white sterile mycelium were comparatively least efficient (data not shown). Many species of genus Aspergillus have also been reported in literature for the biosynthesis of protease [21, 22, 23].

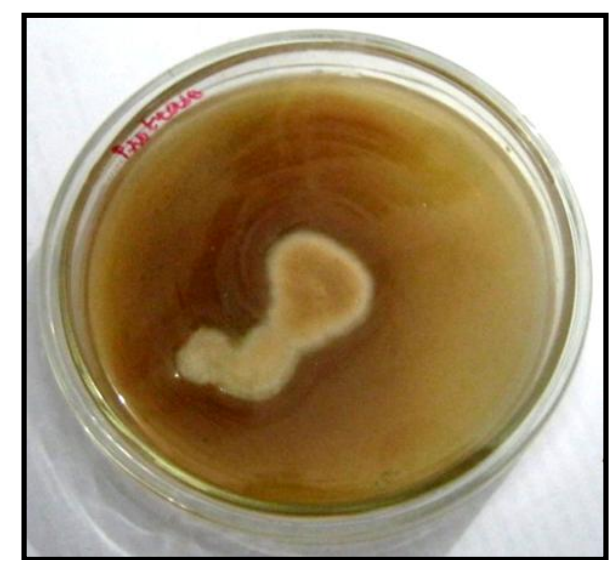

Fig. 4: screening plate of A. terreus NCFT 4269.10 displaying protease activity.

\section{CONCLUSION}

The innate microorganisms of soil mostly respond in three different ways to various chemicals applied. Most of them exhibit a suppressed growth with very low population, some are not greatly affected and few of them are greatly influenced exhibiting high population utilizing the chemicals. The attention may be focused on the sensitive microorganisms that negatively respond to the chemicals applied by greatly reducing the growth and diminish the pattern of transformation of organic and inorganic materials in soil. Though, remarkable developments have been achieved in understanding of the responsibility of soil dwelling organism and their biological action for upholding the soil health; more detailed study is obligatory in achieving feasible protocols for assessment of soil health.

\section{ACKNOWLEDGMENTS}

The authors gratefully acknowledge the financial assistance provided by UGC-RGNF Scheme, New Delhi, India. One of the authors (BKS) also gratefully acknowledges the assistance of Dr. P. N. Chowdhry, Principal Mycologist, National Center of Fungal Taxonomy, New Delhi, India and Prof. Narayan Behera, Former Visiting Professor, P.G. Department of Botany, Utkal University, Bhubaneswar, India in identifying the isolated microorganisms.

\section{REFERENCES}

1. Voets J.P., Meerschman P., Verstraete W. Soil microbiological and biochemical effects of long-term atrazine applicationsSoil Biology and Biochemistry. 1974, 6, 149-152.

2. Duah-Yentumi S., Johnson D.B. Changes in soil microflora in response to repeated applications of some pesticides. Soil Biology and Biochemistry. 1986, 18, 629-635.

3. Rai, J.P.N. Effect of long-term 2,4-D application on soil microbial populations. Biology of Fertile Soils. 1992, 13, 427-431.
4. Dumontet S., Perucci P. The effect of acifluorfen and trifluralin on the size of microbial biomass in soil. The Science and Total Environment. 1992, 123-124.

5. Megharaj M. Kondinin Landcare Group Magazine, Farming Ahead, 2002, 121, 37-38.

6. Smith M.D., Hartnett D.C., Rice C.W. Effects of long-term fungicide applications on microbial properties in tallgrass prairie soil. Soil Biology and Biochemistry. 2000, 32, 935-946.

7. Pankhurst C.E., Doube B.M., Gupta V.V.S.R. Biological Indicators of Soil, edn. 1997.

8. Sannino F., Gianfreda L., Chemosphere. Pesticide influence on soil enzymatic activities. Chemosphere. 2001, 45, 417-425.

9. Johnsen K., Jacobsen C.S., Torsvik V. Pesticide effects on bacterial diversity in agricultural soils-A review. Biology of Fertile Soils. 2001, 33, 443-453.

10. Doran J.W., Parkin T.B. Defining and assessing soil quality. In: JW Doran, DC Coleman, DF Bezdicek and BA Stewart (ed.) Defining Soil Quality for a Sustainable Environment. Soil Science Society of America Special Publication, 1994, 35, pp 3-21.

11. Gregorich E.G., Carter M.R., Doran J.W., Pankhurst C.E., Dwyer L.M. Biological attributes of soil quality. In: EG Gregorich, and Carter MR. (ed,) Soil Quality for Crop Production and Ecosystem Health. Elsevier, 1997, pp. 81-113.

12. Sethi B.K., Nanda P.K., Sahoo S.L. Isolation, Identification And Conservation Of Potent Hydrolase Producer From Different Soils Of Odisha, India. International Journal of Pharma and Bio Sciences. 2013, 4(2)(B), 89-100.

13. Alexopoulos C.J., Mims C.W. Introductory Mycology. 3rd ed., John Wiley and Sons, New York, 1979.

14. Watanabe T. Pictorial Atlas of Soil and Seed Fungi. 2nd Ed., CRC Press, London, 2002.

15. Hankin L., Anagnostakis S.L. The use of solid media for detection of enzyme production by fungi. Mycologia. 1975, 67(3), 597-607.

16. Grant W.D., Mwatha W.E., Jones B.E. Alkaliphiles: ecology, diversity and applications. FEMS Microbiology Review. 1990, 75, 255-70.

17. Fleet G.H., Mian M.A. The occurrence and growth of yeasts in dairy products. Internet Journal of Food Microbiology. 1987, 4, 145-155.

18. Parkinson D., Gray T.R.G., William S.T. Methods for studying the Ecology of soil microorganisms. International Biological Programme Hand book No-19. Black well Scientific Publications, Oxford, 1971.

19. Chakraverty R., Sinha S. Grana. The Incidence of Aspergillus Parasiticus in the Indoor and Outdoor Environments of Calcutta, India. Grana. 1985, 24(2), 133-135.

20. Beg K.Q., Gupta R. Purification and characterization of an oxidationstable, thiol-dependent serine alkaline protease from Bacillus mojavensis. Enzyme and Microbial Technology. 2003, 32, 294-304.

21. Ali U.F. Utilization of whey amended with some agro-industrial byproducts for the improvement of protease production of Aspergillus terreus and its compability with commercial detergents. Research Journal of Agriculture and Biological Science. 2008, 4(6), 886-891.

22. Negi S., Banerjee R. Characterization of amylase and protease produced byAspergillus awamori in a single bioreactor Food Research International. 2009, 42, 443-448.

23. Saravanakumar K., Thiyagarajan A., Kaviyarasan V. Optimization of medium constituents for the production of extra cellular alkaline Protease by As $\mathrm{p}$ e rg illus fis $\mathrm{c}$ h e ri using response surface experimental designJournal of Bioscience Research. 2010, 1(3), 118129.

\section{How to cite this article:}

Bijay Kumar Sethi, Subhashree Pradhan, Narayan Behera and Santi Lata Sahoo. Effect of cypermethrin, a pyrethroid insecticide on dynamics of soil microflora. J App Biol Biotech. 2015; 3 (05): 019-025. DOI: 10.7324/JABB.2015.3504 